\title{
Father-Adolescent Relationship Closeness: A Path Analysis of Family Factor Associates with Father-Adolescent Engagement and Relationship Quality
}

\author{
Mark H. Trahan \\ Texas State University - San Marcos \\ Richard H. Morely \\ Texas State University - San Marcos \\ Kevin Shafer \\ Brigham Young University - Provo, kshafer@byu.edu
}

Follow this and additional works at: https://scholarsarchive.byu.edu/facpub

Part of the Family, Life Course, and Society Commons

\section{Original Publication Citation}

Trahan, M.H., Morley, R.H. \& Shafer, K. Father-Adolescent Relationship Closeness: A Path Analysis of Family Factor Associates with Father-Adolescent Engagement and Relationship Quality. Child Adolesc Soc Work J (2020).

\section{BYU ScholarsArchive Citation}

Trahan, Mark H.; Morely, Richard H.; and Shafer, Kevin, "Father-Adolescent Relationship Closeness: A Path Analysis of Family Factor Associates with Father-Adolescent Engagement and Relationship Quality" (2020). Faculty Publications. 4421.

https://scholarsarchive.byu.edu/facpub/4421

This Peer-Reviewed Article is brought to you for free and open access by BYU ScholarsArchive. It has been accepted for inclusion in Faculty Publications by an authorized administrator of BYU ScholarsArchive. For more information, please contact ellen_amatangelo@byu.edu. 


\title{
Father-Adolescent Relationship Closeness: A Path Analysis of Family Factor Associates with Father-Adolescent Engagement and Relationship Quality
}

\author{
Mark H. Trahan ${ }^{1,3}$ (1) $\cdot$ Richard H. Morley ${ }^{1} \cdot$ Kevin Shafer $^{2}$ \\ C) Springer Science+Business Media, LLC, part of Springer Nature 2020
}

\begin{abstract}
Father-adolescent child relationship quality has been identified as key to adolescent health outcomes. While factors have previously been identified associated with father-adolescent closeness, a comprehensive model of understanding the influence of these factors is needed. Using cross-sectional data from the Study of Contemporary Fatherhood (SCF), this analysis of father-adolescent relationship closeness evaluated responses of nine hundred $(\mathrm{N}=900)$ father surveys to investigate historical factors, including own father relationship quality, biological fathering, family transitions, and ACEs along with current factors, including co-parenting, depression, parenting stress, knowledge of adolescent, warmth, and engagement, on fatheradolescent relationship closeness. Path analysis results indicate that father-adolescent relationship closeness was found to be positively associated with current factors, including co-parenting $(p=.005)$, parenting stress $(p=.008)$, parent depression $(p=.004)$, parent knowledge of adolescent $(p<.001)$, and warmth $(p<.001)$, but not parent engagement. Historical factors, including ACEs, family transitions, family of origin biological father, and own father relationship quality, were not significant predictors of father-adolescent closeness. Implications of this study include the importance of current familial factors on promoting father-adolescent relationship closeness, particularly in family interventions for fathers.
\end{abstract}

Keywords Father $\cdot$ Adolescent $\cdot$ Parenting $\cdot$ Closeness $\cdot$ Path analysis

Historically, researchers have used quantitative measures of fathering behavior (Garfield, Fisher, Barretto, Rutsohn, \& Isacco, 2019; Singley et al., 2018), including time diaries (Cano, Perales, \& Baxter, 2019), observational data (Davison et al., 2016), and self-reports of father involvement and/

This study has exemption from IRB approval. Data from the original study has appeared in multiple publications, including Trahan, M.H., \& Shafer, K. (2019). Paternal self-efficacy: A parenting resilience factor for fathers with depression. Social Work Research, 43(2), 65-128. These data have also been used in previous presentations at the Society for Social Work and Research Annual Conference, the National Council on Family Relations Annual Conference, and Society for Research in Child Development Annual Conference.

\section{Mark H. Trahan}

marktrahan@txstate.edu

Texas State University, San Marcos, TX, USA

2 Brigham Young University, Provo, UT, USA

3 Texas State University School of Social Work, 601 University Drive, Encino Hall \#159, San Marcos, TX 78666, USA or engagement (Dyer, Kauffman, Fagan, Pearson, \& Cabrera, 2018; Pleck, 2010). Generally, these measures evaluate the prevalence or quantity of paternal involvement with a child, using quantifiable scoring to measure interaction. Prominent fatherhood research scholars have recently voiced their concerns that fatherhood related research may undervalue the quality of the parent-child relationship (Fagan, 2020; Palkovitz, 2019), relying too heavily on behavioral measures that may not fully capture the closeness between fathers and children, nor the strength of father-child relationships. The lack of attention to father-child relationship quality within the research literature points to an overall gap in the fathering scholarship, namely how fathers evaluate their relationship with children (Palkovitz, 2019; Trahan \& Cheung, 2018).

The term father engagement has been used interchangeably with father involvement in the research literature (Pleck, 2010). Some have defined engagement as shared activities, characterized by direct father-child contact (Dyer, Kauffman, Fagan, Pearson, \& Cabrera, 2018; Pleck, 2010). Instead of isolated, non-reciprocated activity, father engagement is both the doing and responding of parenting (Pleck, 2010). Pleck 
(2010) proposed that paternal engagement should include five dimensions: positive engagement activities characterized by interaction; warmth and responsiveness; control, including monitoring and decision making; indirect care; and process responsibility. Other theorists have suggested that the Pleck (2010) model overlooks a critical dimension of fathering, the quality of the relationship between the father and child. High relationship quality is the result of bonding and closeness between fathers and their children, implying a personal relationship between father and child (Bretherton, 2010; Palm, 2014). Within the context of a "shared" activity, engagement reflects the father's personalized experience of challenges and rewards associated with a bonded relationship, consisting of moments of emotional quality between a parent and a child. However, neither conceptual (Pleck, 2010), nor operational definitions of engagement explicitly include a dimension of closeness.

Research on fathering with adolescents is lacking, despite its significance in the life course. Adolescence is a key developmental stage requiring new parenting skills and a greater level of monitoring due to independence, social relationships, risk-taking behavior, and potential presentation of mental health challenges (Meeus, 2019). Evaluation of father engagement during adolescence has proven valuable, as evidence mounts that father engagement reduces adolescent aggression, delinquent behavior, externalizing behavior and adolescent female sexual risk-taking behavior (Carlson, 2006; Leon, Jhe Bai, \& Fuller, 2016; Rostad, Silverman, \& McDonald, 2014; Shafer et al., 2017). Furthermore, father engagement boosts adolescent outcomes such as educational achievement (Gordon, 2016), lifetime economic and educational mobility (Sarkadi, Kristiansson, Oberklaid, \& Bremberg, 2008), and prosocial development (Goncy \& van Dulmen, 2010). Bonding and closeness between fathers and children may be of particular value during adolescence (Trahan \& Cheung, 2018). Indeed, it appears from examining limited evidence from father-child relationship quality studies that benefit to children include greater long-term wellbeing, satisfaction, positive mental health (O'Gara, Zhang, Padilla, Liu, \& Wang, 2019; Tornello \& Patterson, 2018), decreased potential for adolescent addiction and sexual risktaking (Habib et al., 2010; Rostad et al., 2014), future adult intimate relationship stability (Hosley et al., 2008), and better health outcomes, such as reduced risk for obesity (Coleman, Caldwell, O'Neil, \& Harris, 2019).

Although studies find a relationship between parent-child relationship quality and child outcomes, there are gaps in understanding factors that associate with father-child relationship closeness. First, studies that focus on fatheradolescent relationship quality generally focus on adolescent outcomes, such as risky sexual behavior (McElwain \& Bub, 2018), mental health (Fanti, Henrich, Brookmeyer, \& Kuperminc, 2008; Van Eijck, Branje, Hale, \& Meeus,
2012), or substance abuse (Moreno, Janssen, Cox, Colby, \& Jackson, 2017). While father engagement, both resident and non-resident, has been found to influence adolescents' health and well-being, there is limited understanding of factors that associate with father-adolescent relationship quality as an outcome. Furthermore, there are relatively few studies that focus on the closeness within the father-adolescent relationship, as most studies attend to involvement and/or engagement. No study to our knowledge compares historical family of origin to current parenting factors as it relates to parentadolescent relationship closeness. Rarely are both historical and current factors evaluated and compared for their associations with father-child relationships. This study is designed to evaluate pathways between potential fathering factors that influence father-adolescent relationship closeness within the context of a comparison of both historical and current parenting factors. To understand father-adolescent relationship closeness, we must first understand the nature of closeness in parent-child relationships.

\section{Background}

Attachment is a specific type of parent-child closeness between a mother and child that promotes a sense of safety, security, and protection for the child's well-being and development (Bowlby, 1973, 1988). Through observational study, Lamb (1975) suggested fathers could be an attachment figure, and that this attachment may revolve around other dimensions, such as play, distinguishing it from attachment to mothers. Questioning the level at which fathers can bond with a newborn (Ainsworth, 1979, 1989), theorists and researchers have come to accept fathers attach differently from mothers, as their window of ability to connect in the early stages of a child's life may be limited (Bowlby, 1988; Diener, Isabella, Behunin, \& Wong Diener, 2008; Goodsell \& Meldrum, 2010; Pleck, 2007). While mothers have ample opportunities to attach with newborns through care, feeding, and nurturing, fathers may not be able to bond in similar ways, reducing their involvement to support of the mother and activities of caregiving such as changing diapers, burping the child after feedings, and holding the child when distressed. These functions, while important, may not actually provide fathers with opportunities for closeness with a child.

Given limited chances to bond in early childhood, greater levels of father-child attachment may occur as the child ages, becoming more communicative and engaged in physical exploration and play (Grossman, Grossman, Fremmer-Bombik, Scheuerer-Englisch, \& Zimmerman, 2002). Stages of physical exploration and play appear to be opportunities for the father to take a more active role in communicating relational messages to the child, resulting in closer feelings of bonding and attachment. 
During child development transitions, the paternal role may change based on changing role expectations and children's needs. Fathers may further attachment bonds when they become a primary source of nurturing to compensate for lack of nurturing from a mother (Goodsell \& Meldrum, 2010). Attachment with a father may also be influenced by child gender throughout the life course of the relationship, including during adolescence (Diener et al., 2008; Keizer, Helmerhorst, \& Gelderen, 2019; Ruiz, Piskernik, Witting, Fulko, \& Ahnert Ruiz, 2018). A fluidity of paternal attachment may run as an undercurrent to father roles and may influence the level of closeness with a child despite the type of involvement.

Paternal closeness, or the degree to which a child experiences both support and conflict in the father-child relationship, is based upon the theory of parent-child attachment (Driscoll \& Pianta, 2011). Closeness with a parent is a dimension of building attachment in parent-child relationships previously defined with characteristics of warmth, openness, and communication that is associated with proximity, such as resident status, and the ability to provide support to the child (Driscoll \& Pianta, 2011; Dyer et al., 2018). As children move into adolescence, parental relationships influence their development, including positive effects on academic performance (Jones, 2004), alcohol consumption (Habib et al., 2010), and self-esteem (Keizer et al., 2019). However, as teenagers face new developmental milestones related to peer relationships and individuation, the relationship between a father and an adolescent may suffer from parent inflexibility and/or limited freedom for autonomy.

A distinction in the nature of the affective relationship between boys and girls and their parents highlight potential differences of close parent relationships based upon child gender. Levels of affective experiences and display, a gateway to closeness in the parent child relationship may vary based upon gender and parent role (Phares, Renk, Duhig, Fields, \& Sly, 2008). Furthermore, the relationship with parents based on child gender may also influence child outcomes. It appears that adolescent gender and the perception of closeness may moderate the transgenerational process of mood related symptoms from fathers to adolescents (Reeb \& Conger, 2009) and may also moderate the association with future internalizing and externalizing behaviors (Steele \& McKinney, 2019), indicating the important role of gender and closeness on family relationships and mental health.

This study attempts to build a comprehensive model for understanding the associations with closeness by designating factors into two groups: historical, or factors from one's family of origin related to the parent-child relationship and current, or factors from the present that may be influential in the parent-child relationship. Furthermore, these factors have been identified as potential variables related to both paternal closeness and engagement.

\section{A Father's History: Potential Links to Relationship Closeness with an Adolescent}

A father's relationship with his own father may impact his self-concept, shaping the relationship quality he has with his children (Dick, 2011; Palm, 2014). The rationale for this assertion includes the strength of men's expectations for fathering based on lived experience as a child, role modeling of paternal behavior from one's father, and paternal deprivation leading to a compensatory response to father absence (Beaton \& Doherty, 2007; Cook, Jones, Dick, \& Singh, 2005; Jessee \& Adamsons, 2018). Compensatory theory of fathering (Coltrane, 1996; Gaunt \& Bassi, 2012) identifies an internal motivation for some men who were not fathered to compensate; thus, increasing their attention and focus on the relationship with their child. Theory of Planned Behavior (Fishbein \& Ajzen, 1975), suggests that intention has a strong influence over behavior, even within the context of social norms and perceived behavioral control. Within this theoretical context, fathers who set an intention to parent their child or adolescent differently may have stronger engagement with an adolescent due to their increased focus on their parenting. The quality of one's relationship with their father may influence closeness in family relationships, generally encouraging the transmission of paternal multi-generational closeness (Madigan, Benoit, \& Boucher, 2011; Madigan, Atkinson, Laurin, \& Benoit, 2013). Recent work on the effect of multi-generational processes related to father-child relationship quality appears to support the premise that paternal child relationship quality has a prospective quality, namely that grandfather to father relationships set a precedent for father-child relationships (Jessee \& Adamsons, 2018).

Furthermore, it does appear that the changes in family constellation with a stepparent present may influence both adolescent health outcomes and levels of closeness within nuclear family relationships (Amato, King, \& Thorsen, 2016). Nonbiological parenting, including stepparenting and cohabitating non-bio parents, may reduce the quality of the father-child relationship (Bray \& Easling, 2005; Hofferth \& Anderson, 2003). Biological fathering appears to promote a much greater benefit to adolescents, boosting involvement, warmth, and quality of the parent-child relationship (Hofferth \& Anderson, 2003; Yoon et al., 2020). However, little is known about the transgenerational process of biological parenting on the quality of relationships with children. Historical experiences with a non-bio parent have not been evaluated for their effect on the quality of parent relationship with an adolescent child.

Adverse childhood experiences (ACEs) is a measure of traumatic childhood events, such as childhood exposure 
to abuse or neglect, domestic violence, mental illness, substance abuse, and criminal behavior (Anda, Butchart, Felitti, \& Brown, 2010; CDC, 2019a). Research consistently identifies ACEs as a key factor in future mental and physical health, risky sexual behavior, and educational, occupational, and income trajectories (CDC, 2019a). Prior evaluation of the effect of ACEs on parenting behavior indicate associations with parenting aggression, levels of hostility, decreased warmth and more potential for abuse and neglect (Banyard, Williams, \& Siegel, 2003; DiLillo, Tremblay, \& Peterson, 2000; Hughes \& Cossar, 2016; Pazdera, McWey, Mullis, \& Carbonell, 2013; Schuetze \& Eiden, 2005; Thornberry, Knight, \& Lovegrove, 2012). Furthermore, parental exposure to ACEs may be associated with increased risk of child developmental delay, negatively affecting child problem solving, communication, social interaction, and motor skills (Folger et al., 2018). The experience of ACEs in childhood may have implications for later adult secure attachment relationships, as traumatic experiences may increase the potential for insecure attachment even in non-clinical samples (Thomson \& Jaque, 2017). Furthermore, utilizing the standard categories of attachment diagnosed by the Adult Attachment Inventory (AAI), clinical and community samples demonstrate greater likelihood of categorizing those with four or more positive ACE items as unresolved mourning (U) due to past trauma or discordant states of mind or cannot classify (CC) interviews (Murphy et al., 2014). Unfortunately, these two categories (U/CC) associate poorly with parenting skills, with a greater likelihood of parent to child responses of frightened, threatening or dissociative behavior leading to greater potential for disorganized attachment in children (Hesse \& Main, 2006). Traumatic experiences are often associated with problems related to depression, anxiety, and general health problems, which may affect parenting closeness (Anda, Butchart, Felitti, $\&$ Brown, 2010; CDC, 2019a). When parents suffer from these mental and physical health disabilities, they are less likely to attend to children's needs. Many studies related to ACEs primarily sample mothers, leaving gaps of knowledge about the influence of ACEs in fathering, with a dearth of evidence about effects on paternal-adolescent relationships.

A history of significant family transitions such as separation and divorce are considered ACEs, as children are more likely to experience stress and anxiety as a result (Jensen, Shafer, \& Holmes, 2017). Family transitions, including marital and cohabitation transitions in family structure and composition, have long been identified as relevant to child development (Brown, 2006). Children and adolescents experiencing multiple family transitions are more likely to exhibit internalized and externalized symptoms, reduced cognitive and socioemotional development, symptoms of delinquency, and reduced academic engagement (Brown, 2006; Lee \& McLanahan, 2015). Disruptions such as divorce, remarriage, blending families, and stepparent introduction present potential challenges in the parent-child relationship as well. However, less is known about the historical effect of family of origin transitions on the quality of future parent-child relationships, specifically father-adolescent relationship closeness.

\section{The Present: Current Parenting Environment for Adolescence}

A history of research related to paternal engagement indicates that a father's involvement in the parenting realm is important for child outcomes. As the child ages, father involvement is a key determinant of the attachment level between father and child (Brown, Mangelsdorf, \& Neff, 2012). Parental warmth and monitoring behavior are also important factors for these outcomes, for children with warmth from a father are more likely to gain social skills and exhibit pro-social behavior (Padilla-Walker, Nielson, \& Day, 2016; Webster, Low, Siller, \& Hackett, 2013). Warmth within the parenting realm in general has been linked to adolescent development outcomes such as delinquency (Hoeve et al., 2009), depression and anxiety (Yap, Pilkington, Ryan, \& Jorm, 2014), academic achievement (Pinquart, 2015), and externalizing behavior problems (Pinquart, 2017). However, little work has focused on the relationship between engagement, warmth, and father closeness, and these factors remain important for understanding child and family relationships.

While it is developmentally appropriate for adolescents to become more secretive, less transparent, and more autonomous (Lionetti et al., 2019), parental monitoring has demonstrated strong effects on risky adolescent sexual behavior (Dittus et al., 2015), adolescent alcohol consumption (Yap, Cheong, Zaravinos-Tsakos, Lubman, \& Jorm, 2017), and adolescent delinquency (Keijsers, 2016). However, parental monitoring has historically been based upon the concept of parental knowledge related to an adolescent, not solicitation or monitoring of behavior (Stattin, Kerr \& Tilton-Weaver, 2010). More recently, questions have been posed about the construct of parental monitoring (Stattin et al., 2010), thus leading a re-evaluation of the construct of parental monitoring by identifying previous research construct measurement as a parent's knowledge of their child rather than parental monitoring. As many studies have previously used parental knowledge as a construct to measure monitoring behavior, there are strong associations between parenting knowledge and adolescent outcomes (Guilamo-Ramos, Jaccard, \& Dittus, 2010). Most studies related to parental monitoring include both mothers and fathers, with few providing a 
specific model of the associations between paternal knowledge of their child, engagement, and relationship quality.

Mental health and stress may also affect the father-adolescent relationship closeness. Fathers who are depressed are less likely to exhibit warmth and engage with their children (Shafer, Fielding, \& Holmes, 2019). They are also more likely to exhibit aggression, negative affect, and behave in an abusive or neglectful manner (Bronte-Tinkew, Moore, Matthews, \& Carrano, 2007; Epkins \& Harper, 2016; Leung \& Smith Slep, 2006; Nath, Russell, Ford, Kuyken, \& Psychogiou, 2015). Depression often contributes to a negative cognitive perspective, which can be detrimental in seeing the positive and providing a child with a positive affirmative experience. Parenting stress has also been found to impact the closeness of parenting relationships (Nygren, Carsten, Ludvigsson, \& Sepa Frostell, 2012). While limited in research related specifically to fathers, parenting stress in fathers has been associated with lower cognitive score ranges in children (Harewood, Valloton, \& Borphy-Herb, 2017). Parenting stress may be a contributor to the overall lack of attention to a child's needs.

Lastly, the co-parenting relationship has been a focus of research related to the paternal relationship with a child, particularly with low-income, non-resident fathers. Co-parenting is the degree to which two parents (not necessarily biological) work together to share activities that provide care for a child (McHale \& Lindahl, 2011). Ideally, the co-parenting alliance provides support and shared decision making with another in the active pursuit of care. This relationship quality between parents and critical evaluations of infant care may decrease the likelihood of father infant closeness (Carlson, Pilkauskus, McLanahan, \& Brooks-Gunn, 2011; Wynter, Rowe, Tran, \& Fisher, 2016). With non-resident fathers, coparenting challenges may increase due to the relationship status and risks for his participation in the parenting process, including income and distance (Fagan \& Palkovitz, 2007). When a co-parenting relationship is positive, fathers are more likely to engage in involvement with children (Coates $\&$ Phares, 2014). However, less is known about the intersection of coparenting and father relationship quality within the context of the father-adolescent relationship.

The goal of this exploratory study is to explore a broad range of factors that may be associated with father-adolescent closeness. We do this by evaluating the associations of family of origin experiences and current fathering factors on variables of engagement and father-adolescent closeness. Engagement has also been included as a dependent variable to compare the paths of historical and current factors to both dependent variables. Furthermore, engagement is potentially associated with father-adolescent closeness and was thus included in the model. These factors were chosen to represent previously researched factors associated with involvement and engagement, along with new variables that were hypothesized to relate to father-adolescent closeness. We recognize, however, that there may be other factors previously researched related to paternal engagement, not included in our analysis. For instance, paternal sensitivity has previously been evaluated as an important personality characteristic contributing to attachment (Grossman, Grossman, \& Kindler, 2005; Lucassen et al., 2011).

In addition to a study of exploratory factors that may associate with father-adolescent relationship closeness, this study subdivides factors into two categories: factors from one's family of origin, which we will name "historical" and factors that relate to the current experience of parenting an adolescent, which have been named "current." These designations are also an opportunity to cross-compare differences between factors experienced in childhood that later may impact relationship quality with current factors. Recognizing that these factors are retrospective, we acknowledge that memory influence may be attached to the validity of historical variables, as they are self-reported by participants. Historical factors, in this study, include the history of a quality relationship with a paternal figure and whether that parent was a biological parent, a history of ACEs, and the number of family transitions during childhood. Current factors include parenting warmth, parent knowledge of their child, mental health, parenting stress, and the quality of the co-parenting relationship. As paternal engagement is also potentially a factor related to the closeness of a parent-adolescent relationship, we also include engagement as a factor for the model.

Based on prior research, we hypothesize the following:

1. Historical influences of own father relationship quality, biological parenting, ACEs, and family transitions be associated with paternal engagement and father-adolescent relationship closeness. Own father relationship quality will be positively associated with father-adolescent closeness, while ACEs, family transitions, and nonbiological parenting will be negatively associated.

2. Current parental warmth and parent knowledge of adolescent and factors that may affect these traits, including parenting stress, depression, and co-parenting quality, will be associated with paternal engagement and father-adolescent relationship closeness. While paternal warmth, knowledge of adolescent and co-parenting will demonstrate a positive association with relationship quality, parenting stress and depression will demonstrate a negative association. 


\section{Methods}

\section{Participants and Data Collection}

This study is a secondary data analysis from the Survey of Contemporary Fatherhood (SCF) in 2015 (For more information, see Shafer, Fielding, \& Holmes, 2019). The survey is a cross-sectional online survey research design that collected data related to factors that relate to contemporary fatherhood in the United States. SCF is a national sample of nearly 2300 biological, stepfathers, and father figures collected by multiple investigators from universities across the United States. Survey eligibility requirements included: (1) at least 18 years of age, (2) a paternal relationship with a child including biological (resident and non-resident), adoptive (resident and non-resident), stepparent (resident only), nonbiological related resident father figure (i.e., nonbiological and not adopted paternal relationship with a child, living in the home but not married to the child's biological or adoptive mother), and biological related father figure (resident, related by biology, marriage, or adoption such as grandfather or uncle), (3) English proficiency, and (4) Internet access for survey completion. Respondents were asked to use their youngest child (between 2 and 17 years of age) as a focal relationship to answer questions.

Quota sampling techniques were employed for data collection. Samples collected using quota sampling have produced equivalency to probability samples (Weinberg, Freese, \& McElhattan et al., 2014), but may also produce non-equivalent samples (Yang \& Banamah, 2014). Due to self-selection bias and survey collection based on quota stratification, quota sampling cannot be interpreted as representative. Thus, results from this study should be considered exploratory in nature. Data was collected using a Qualtrics opt-in online panel, recruited through online and other advertising, and screened for eligibility through an online registration form. Approximately 9,000 respondent candidates were randomly selected by Qualtrics from a pool of approximately 17.6 million potential participants and contacted via email, text message, or other electronic means by Qualtrics to request participation. Respondents were provided a link to the survey screening site, where final eligibility was determined based upon three categories: race and ethnicity, paternal relationship with child, and geographical residence. The final response rate from randomly chosen panelists was $26.2 \%$. Quotas of population characteristics were drawn from population estimates from the 2011 to 2014 American Community Survey (U.S. Census Bureau, 2016). Upon meeting eligibility requirements, respondents were invited to complete the survey.

Data quality checks, including attention filters (sometimes referred to as "trap questions"), identification of careless respondents, guards against multiple submissions, and survey length minimums were all employed - in accordance with the guidelines for online survey implementation approved by the American Association for Public Opinion Research (AAPOR) (Baker et al., 2010). Online research designs can be representative of those that have access to the Internet (Tourangeau, Conrad, \& Couper, 2013). For this reason, generalizability may be impacted by access to technology. Father demographics in SCF are like other national data sets (see Shafer et al., 2019), including Pew Research, Survey of American Fathers (race/ethnicity, education, and income), and National Survey of Family Growth (resident status). However, there are groups within the SCF that are underrepresented compared to national statistics, including non-resident, low SES, and minority fathers. While the results of this study should not be considered generalizable, the large sample size and quality of measures used should be considered a resource for exploring the nature of paternalchild relationships.

Fathers answered questions related to a focal child. Only fathers reporting that the focal child was an adolescent, defined by the World Health Organization (WHO) as ages 10-19, were included in the analytic analysis (Rosen, 2004). While the WHO extends adolescence to 19 years of age, this study did not include fathers with children over the age of 18 , which is generally a cut-off point for moving to adult status. Additionally, only fathers who reported as the biological, stepparent, or adopted father to a child were included in the analysis. Twenty-five fathers were removed from the analysis due to their status as a foster parent, guardian, grandfather, extended family member, or currently residing with a child of a girlfriend.

\section{Measures}

\section{Father-Adolescent Closeness}

Relationship quality with a child was measured using an agespecific measure of parent-adolescent relationship quality from NICHD Study of Early Childcare and Youth Development (SECCYD) (U.S. Dept. of Health and Human Services, 2019). The Parent-Adolescent Relationship Quality Scale (Hair et al., 2006) consists of 8 items measuring the level of closeness in a parent-adolescent relationship with respondents using a 5 -point Likert-like scale $(1=$ strongly agree to $5=$ strongly disagree) to assess the parental report of the quality of closeness with their adolescent (e.g., they consistently turn to you when upset or worried, they seek you out when something bad happens) with several items reverse coded (e.g., they depend on you too often). The scale demonstrates good internal consistency $(\alpha=0.80)$. 


\section{Paternal Engagement}

Father engagement scales were employed to be ageappropriate, with the current study utilizing the National Survey of Family Growth (NSFG) scales of involvement (CDC, 2019b). The NSFG scale (2006-2010) consists of 13 items for fathers of children ages 9-18 quantifying father involvement. Respondents answer questions on a five-point Likert-like scale $(1=$ not at all to $5=$ every day) about the frequency of behavior (e.g., eat evening meals together, take him/her to the doctor, help them when they were upset). The scale demonstrates good internal consistency $(\alpha=0.89)$.

\section{Historical Factors}

Adverse Childhood Experiences The Adverse Childhood Experiences Questionnaire was employed to evaluate the effect of retrospective abuse, neglect, and household dysfunction during childhood. The scale has consistently demonstrated reliability (Bethell et al., 2017) and been used in large scale data collection related to the effects of childhood trauma (Anda, Butchart, Felitti, \& Brown, 2010). The questionnaire consists of 18 items with a binary response of "yes" or "no" totaled to create a cumulative score to measure the quantity of ACEs. The scale demonstrates good internal consistency $(\alpha=0.88)$.

Family Transitions Family transition has been identified as a significant stressor with the potential to affect future adolescent development (Brown, 2006; Jensen et al., 2017). Family transitions are defined as changes in structure, resulting in new family composition. To measure family transitions, respondents were requested to state how many years they lived in various family structures. These family compositions included "both biological parents," single parent (because of divorce), single parent (because of death), biological parent, and stepparent, single parent (never married), foster family, two adoptive parents, a relative other than a parent, biological parent and partner (not married), and single adoptive parent. A cumulative score of the number of transitions was calculated by adding up the amount of transitions in a family structure from ages 0 to 18 years of age.

Family of Origin (FOO) Father Quality Measurement of the family of origin father quality consisted of two variables: growing up with a biological father and the quality of the father-child relationship. Growing up with a biological father was measured using a dichotomous variable of biological and all other types of father relationships. The quality of the FOO fathering was measured using the 9-item RELATE family of origin father-child relationship scale
(Busby, Holman, \& Taniguchi, 2001). Respondents use a 5-point Likert-like scale to answer questions about the quality of their experience with someone they identify as their "father" (e.g., How much do you think your father enjoyed being a father?, When you needed a father's support, was he there for you?). Test-retest reliability of the original scale indicates good reliability $(\alpha=0.86)$ and current scale demonstrates excellent internal consistency $(\alpha=0.96)$.

\section{Current Factors}

Depression Depression was measured with the 20-item Center for Epidemiological Studies-Depression (CES-D) scale (Comstock \& Helsing, 1976), which addresses the frequency of both internalized (e.g., "I had trouble keeping my mind on what I was doing") and externalized symptoms (e.g., "I did not feel like eating, my appetite was poor") over the last week. For each of the 20 items on the scale, respondents were asked to indicate how frequently they experienced the depressive symptom on a four-point Likert-like scale ranging from 0 (did not experience in the last week) to 3 (experienced every day or almost every day in the last week). Using standardized scoring instructions for this scale, results were calculated by summing all 20 items into a continuous variable ranging from 0 to 60 . This scale demonstrates high internal consistency $(a=0.92)$ and has shown acceptable sensitivity and specificity in various analyses (e.g., Thomas et al., 2001).

Knowledge of Adolescent Knowledge of adolescent, or parental involvement and monitoring (for more information about this distinction, see Stattin et al., 2010) was measured utilizing the 9-item parental monitoring or "keeping tabs" scale from Phase IV of the SECCYD study (U.S. Dept. of Health and Human Services, 2019). Respondents use a fourpoint Likert like scale $(1=$ not at all, $2=$ a little bit, $3=a$ lot, $4=$ everything) to respond to questions related to the amount of knowledge they maintain about their child (e.g., who they spend time with, where they go after school, how they spend their money). Using scoring instructions from this scale, results were calculated by summing all items into a continuous variable. The scale demonstrates excellent internal consistency $(\alpha=0.90)$.

Warmth Warmth was measured using the 17-item parenting warmth scale from SECCYD, Phase IV (U.S. Department of Health and Human Services, 2019). Using a fourpoint Likert like scale $(1=$ never, $2=$ sometimes, $3=$ often, $4=$ always), respondents are asked about the frequency of behavior during interaction related to the amount of warmth between parent and child (e.g., let them know you really care about them, act supportive and understanding towards them, let them know you appreciate them, their ideas, or the 
things they do). Eight items are reverse scored (e.g., criticize them or their ideas). Using scoring instructions from this scale, results were calculated by summing all items into a continuous variable. The scale demonstrates good internal consistency $(\alpha=0.89)$.

Parenting Stress Parenting stress was measured using a 5-item adapted version of the parenting stress scale (Osborne \& McLanahan, 2007). Using a four-point Likert like scale $(1=$ never, $2=$ rarely, $3=$ sometimes, $4=$ often $)$, respondents indicate their level of agreement with statements related to well-being regarding being a parent (e.g., I enjoy being a parent). Several items are reverse scored (e.g., as a parent, I often feel I cannot handle things well), and a total score is calculated by summing all items. The longer version of the scale has demonstrated excellent internal consistency $(\alpha=0.89$; Osborne \& McLanahan, 2007), and the adapted version demonstrates acceptable internal consistency $(\alpha=0.77)$.

Co-parenting Co-parenting support was measured using the five items from the Fragile Families and Child Wellbeing Study, Y1, Y3, and Y5. The items measure the degree to which a father feels supported by the mother of the child. Sample items include "you and mother talk about problems that come up with raising your child" and "she supports you in the way you want to raise your child." Using the 3 item Likert-like scale from Y1, respondents state how often statements are true $(1=$ always, $2=$ sometimes, $3=$ never $)$. Items are then reverse scored and summed to construct a composite score of perceived co-parenting support. The measure demonstrates excellent internal consistency $(\alpha=0.91)$.

\section{Control Variables}

Control variables were also included in the model to increase model fit. Dichotomous variables were created for categorical variables. Using model building techniques (Hosmer, Lemeshow, \& Sturdivant, 2013), Pearson's correlation coefficients were analyzed for association with dependent variables. These included race ( $1=$ Caucasian, $0=$ Minority), residential status of the child $(1=$ Resident, $0=$ Non-Resident), father's employment status ( $1=$ Stay at Home Parent, $0=$ Employed part or full time, other), and biological status to adolescent $(1=$ biological father, $2=$ stepchild, foster, adopted, and other).

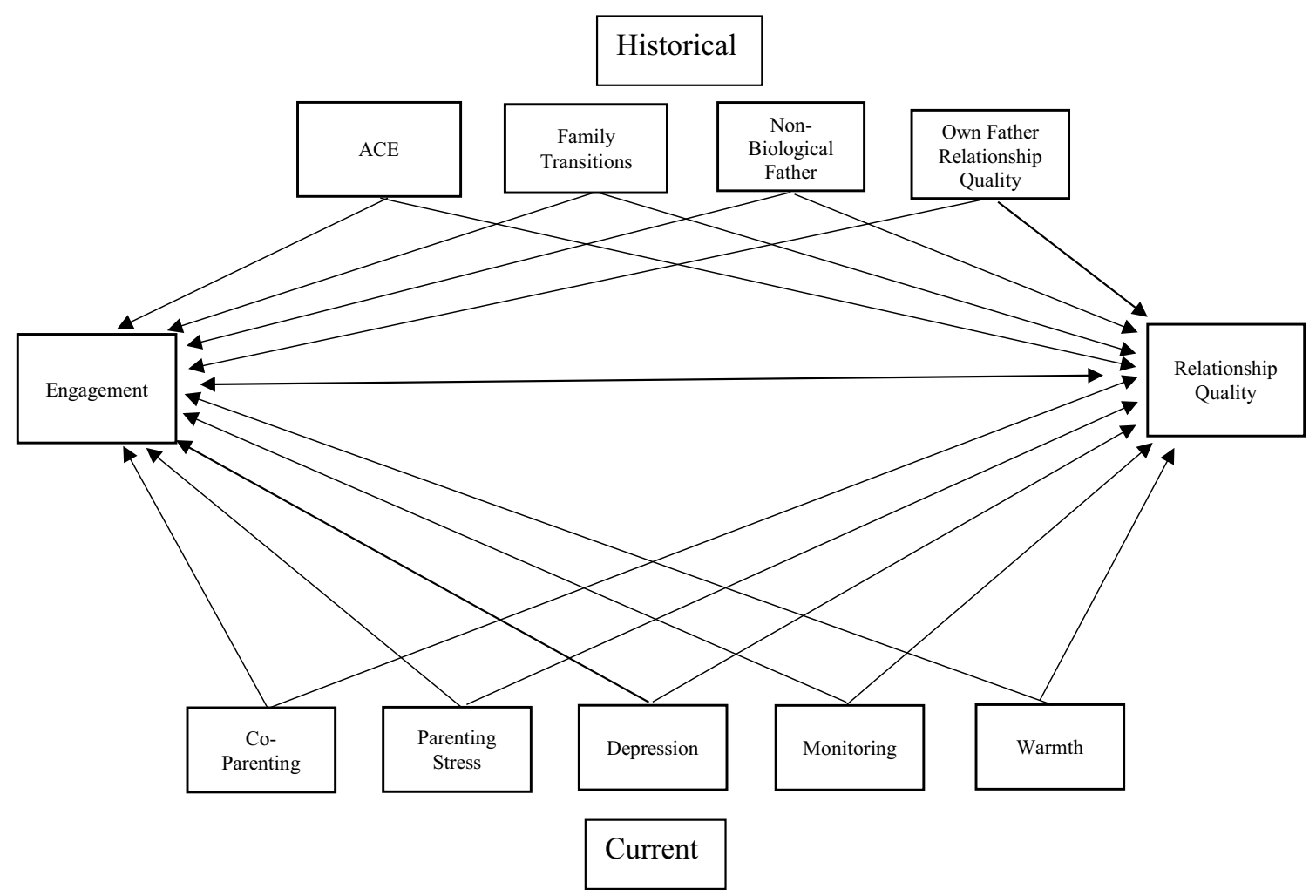

Fig. 1 Path analysis of historical and current factors related to engagement and father-adolescent relationship closeness 


\section{Results}

\section{Analytic Approach}

Path analysis was conducted to ascertain the associations between historical and current factors on parental engagement and relationship closeness (see Fig. 1). This analysis included the effects of only manifested variables on paternal engagement and relationship quality. Variables were also entered in the path analysis to control for demographic factors. Pearson's correlation coefficients were calculated to determine the correlation between demographic variables and dependent variables. Only variables of parent race, child age, child gender, child residential status, and parent employment status correlated with the dependent variables, paternal engagement and father-adolescent relationship closeness. Thus, those factors were included in the analysis. Engagement was also included in the model. Therefore, the path analysis consisted of both engagement and relationship closeness as dependent variables, with factors related to each evaluated for correlation. Furthermore, a pathway between engagement and relationship closeness was introduced to evaluate whether there was an association and potential overlap between these two constructs. As engagement may be highly associated with relationship closeness, it was determined to be evaluated as both a dependent and independent variable. The investigation involved testing a covariance matrix to a maximum likelihood function using STATA SE 15.0 (StataCorp., 2017).

Indicators of the goodness of fit for the model were assessed, including assessing whether chi-square is nonsignificant, Steiger and Lind Root Mean Square Error of Approximation (RMSEA) is less than 0.06 (Browne \& Cudeck, 1992; Lance, Beck, Fan, \& Carter, 2016), a Comparative fit index (CFI) of at least 0.95 (Lance et al., 2016), a Tucker-Lewis Index (TLI) of at least 0.95 (Hu \& Bentler, 1999; West, Taylor, \& Wu, 2012) and a Standardized Root Mean-Square Residual (SRMR) is less than 0.05. Generally, chi-square is the prominent index of model fit. However, there may be limitations particularly related to large sample size, causing chi-square to be significant, despite just identified model fit. Thus, other indices are included to address this potential limitation.

\section{Sample Description}

Nine hundred thirty-three surveys were initially reviewed for inclusion/exclusion criteria. Of these, 33 surveys included father figures, which were excluded from the final study. The remaining sample $(\mathrm{N}=900)$ were evaluated for missing data using Little's MCAR test (Little, 1988). Little's test was significant $($ chi-square $=55.52 ; p=0.001)$, indicating potential MNAR or MAR data. Upon review of the data, it appears that the data is MNAR, and missing data accounts for $0.65 \%$ of data from variables of interest, indicating a low potential for bias.

The sample $(\mathrm{N}=900)$ consisted of fathers, ages 18 to 72 $(\mathrm{m}=44.91, \mathrm{SD}=9.63)$ including biological fathers $(80.9 \%$; $n=728$ ) and nonbiological fathers (stepfathers, adoptive fathers) $(19.1 \%, n=172)$ with self-identified racial categories consisting of Caucasian/white $(76.9 \% ; n=692)$, African American $(9.5 \% ; n=86)$, Latino/Hispanic $(5.6 \% ; n=51)$, Multi-racial (3.5\%; $n=32)$, Asian $(3.2 \%, n=29)$, Native American $(n=7)$ and Other $(n=4)$. Education levels varied, with fathers reporting high school education including a GED or below $(19.7 \% ; n=178)$, some college $(n=222$; $24.6 \%)$, associate degree $(13.0 \%, n=117)$, bachelor degree $(28.6 \%, n=258)$, and some or completed graduate education $(13.9 \%, n=125)$. Father's personal income was also varied; however, most fathers reported an income between $\$ 20,000$ and $\$ 79,000(n=555,61.6 \%)$. Half of fathers $(n=458$, $50.9 \%$ ) were married for the first time, with others reporting being remarried $(n=158,17.6 \%)$, or unmarried including divorced/separated, cohabitating, or engaged ( $n=177$, $19.6 \%)$. Most fathers reported current employment, either by wages or self-employed $(n=773,85.8 \%)$. Focal children of survey answers were both male $(56.1 \%, n=505)$ and female $(43.9 \%, n=395)$. Descriptive statistics are reported in Table 1.

\section{Correlation and Path Analysis}

The analyses consisted of Correlational and Path Analysis. The Correlation Matrix is displayed in Table 2. The first analysis consisted of current and historical factors associated with father engagement. The correlational analysis revealed that father engagement was positively correlated with current factors including father-adolescent relationship closeness $(\mathrm{r}=0.15, p=0.000)$, co-parenting $(\mathrm{r}=0.11, p=0.001)$, knowledge of child $(\mathrm{r}=0.40, p=0.000)$, warmth $(\mathrm{r}=0.22$, $p=0.000)$ and negatively correlated with parenting stress $(\mathrm{r}=-0.131, p=0.000)$ with no association with depression $(\mathrm{r}=0.02, p=0.555)$. Father engagement was also positively correlated with historical factors including family transitions $(\mathrm{r}=0.10 p=0.005)$, ACEs $(\mathrm{r}=0.10, p=0.004)$, and own father relationship quality $(\mathrm{r}=0.16, p=0.000)$, but was not found to correlate with having a nonbiological father $(\mathrm{r}=-0.02, p=0.597)$.

The second analysis consisted of associations between factors and father-adolescent relationship closeness. Father-adolescent relationship closeness was found to be positively correlated with current factors including father engagement $(\mathrm{r}=0.15, p=0.000)$, co-parenting $(\mathrm{r}=0.30$, $p=0.000)$, knowledge of adolescent $(\mathrm{r}=0.42, p=0.000)$, and warmth $(\mathrm{r}=0.65, p=0.000)$, and negatively correlated 
Table 1 Descriptive statistics $(\mathrm{N}=900)$

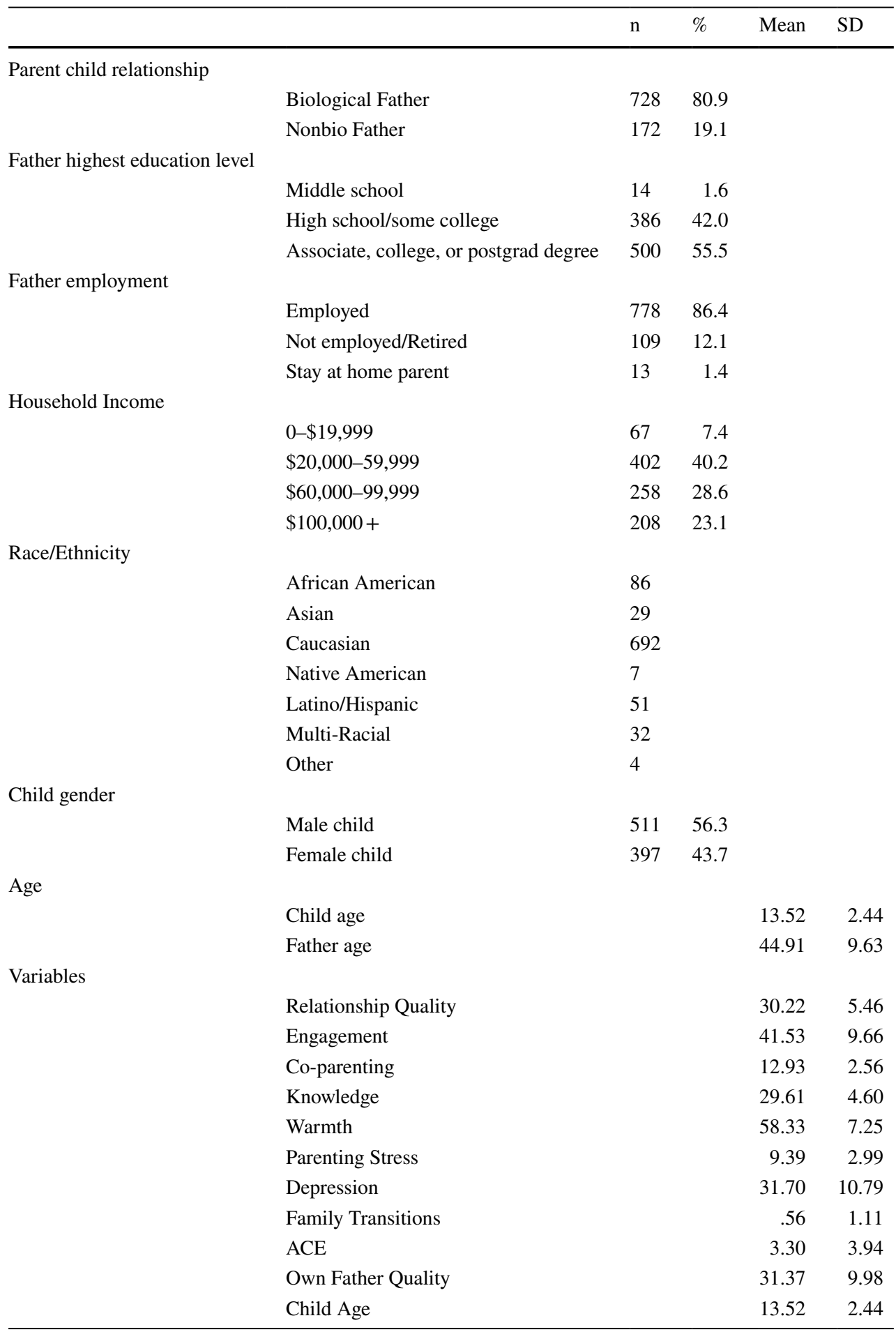

with parenting stress $(\mathrm{r}=-0.43, p=0.000)$ and depression $(\mathrm{r}=-0.36, p=0.000)$. In analyzing historical factors, fatheradolescent relationship closeness did positively correlate with own father quality $(\mathrm{r}=0.07, p=0.048)$, but did not associate with ACEs $(\mathrm{r}=-0.05, p=0.116)$ or nonbiological fathering $(\mathrm{r}=-0.01, p=0.735)$. A negative correlation was demonstrated with family transitions $(\mathrm{r}=-0.07, p=0.038)$ (Table 2).

Path analysis was conducted to test the model displayed in Fig. 1 while controlling for Race, Child Age, Child Gender, Father Residential Status, Employment, and Relationship with Child (Table 3). The model was found to be justly identified; $\chi^{2}=783.78, p=0.000, R M S E A=0,95 \%$ 
Table 2 Pearson correlation coefficients among study variables $(\mathrm{N}=900)$

\begin{tabular}{|c|c|c|c|c|c|c|c|c|c|c|c|}
\hline & Eng & Close & CoPar & ParS & Depr & Know & Warm & $\mathrm{ACE}$ & FamTr & Bio & OFRQ \\
\hline Eng & 1 & & & & & & & & & & \\
\hline Close & $.15^{* *}$ & 1 & & & & & & & & & \\
\hline CoPar & $.11 * *$ & $.30 * *$ & 1 & & & & & & & & \\
\hline ParS & $-.13^{* *}$ & $-.43^{* *}$ & $-25^{* *}$ & 1 & & & & & & & \\
\hline Depr & .02 & $-.36 * *$ & $-.31 * *$ & $.41 * *$ & 1 & & & & & & \\
\hline Know & $.40^{* *}$ & $.42 * *$ & $.19^{* *}$ & $-.28 * *$ & $-.18^{* *}$ & 1 & & & & & \\
\hline Warm & $.22 * *$ & $.64 * *$ & $.32 * *$ & $-.48^{*}$ & $-.40 * *$ & $.44 * *$ & 1 & & & & \\
\hline $\mathrm{ACE}$ & $.10^{* * *}$ & -.05 & $-.14 * *$ & $.15^{* *}$ & $.33 * *$ & .00 & $-.07 *$ & 1 & & & \\
\hline FamTr & $.10^{* * *}$ & $-.07 *$ & -.06 & .06 & $.15^{* *}$ & .01 & $-.09 *$ & $.38 * *$ & 1 & & \\
\hline Bio & -.02 & -.01 & -.01 & .01 & -.02 & -.00 & -.02 & $-.20 * *$ & $-.31 * *$ & 1 & \\
\hline OFRQ & $.16^{* *}$ & $.07 *$ & $.14^{* *}$ & $-.14^{* *}$ & $-.19 * *$ & $.13^{* *}$ & $.09 * *$ & $-.45^{* *}$ & $-.20 * *$ & $.14 * *$ & 1 \\
\hline
\end{tabular}

* $\mathrm{p}<.05 * * \mathrm{p}<.01$

Eng engagement, Close father-adolescent closeness, CoPar co-parenting, ParS parenting stress, Depr depression, Know parent knowledge, Warm warmth, FamTr family transitions, Bio biological father, $O F R Q$ own father relationship quality

Table 3 Path analysis results $(\mathrm{N}=900)$

\begin{tabular}{|c|c|c|c|c|c|c|}
\hline Variable & Coef & OIM Std. Err & $\mathrm{Z}$ & $\mathrm{P}>|\mathrm{z}|$ & 95\% Conf. Interval & \\
\hline \multicolumn{7}{|l|}{ Engagement } \\
\hline Race & -3.45 & 0.74 & -4.68 & 0.00 & -4.89 & -2.00 \\
\hline Resident child & 4.61 & 1.10 & 4.17 & 0.00 & 2.44 & 6.77 \\
\hline Stay at home parent & -2.25 & 2.40 & -0.94 & .0 .35 & -6.97 & 2.46 \\
\hline Biological status to adolescent & 1.45 & 0.84 & 1.73 & 0.08 & -0.20 & 3.09 \\
\hline Warmth & 0.14 & 0.05 & 2.68 & 0.00 & 0.04 & 0.24 \\
\hline Depression & 0.12 & 0.03 & 3.68 & 0.00 & 0.06 & 0.18 \\
\hline Parenting stress & -0.11 & 0.12 & -0.98 & 0.33 & -0.34 & 0.11 \\
\hline Own Father Quality & 0.19 & 0.03 & 5.75 & 0.00 & 0.13 & 0.26 \\
\hline ACEs & 0.31 & 0.09 & 3.42 & 0.00 & 0.13 & 0.49 \\
\hline Family Transitions & 0.92 & 0.29 & 3.18 & 0.00 & 0.35 & 1.49 \\
\hline Knowledge & 0.67 & 0.07 & 9.12 & 0.00 & 0.52 & 0.81 \\
\hline Historical nonbiological father & -1.57 & 1.03 & -1.52 & 0.13 & -3.59 & 0.45 \\
\hline Co-parenting & 0.07 & 0.13 & 0.55 & 0.58 & -0.18 & 0.32 \\
\hline \multicolumn{7}{|l|}{ Closeness } \\
\hline Race & 0.99 & 0.35 & 2.80 & 0.01 & 0.30 & 1.68 \\
\hline Resident Child & 0.46 & 0.53 & 0.87 & 0.39 & -0.58 & 1.50 \\
\hline Stay at home parent & -2.89 & 1.15 & -2.50 & 0.01 & -5.16 & -0.62 \\
\hline Biological status to adolescent & 0.76 & 0.38 & 1.99 & 0.05 & 0.01 & 1.53 \\
\hline Warmth & 0.37 & 0.02 & 14.77 & 0.00 & 0.32 & 0.41 \\
\hline Depression & -0.03 & 0.02 & -2.12 & 0.03 & -0.06 & -0.002 \\
\hline Parenting Stress & -0.22 & 0.06 & -3.99 & 0.00 & -0.33 & -0.11 \\
\hline Own Father Quality & -0.01 & 0.02 & -0.52 & 0.60 & -0.04 & 0.02 \\
\hline ACEs & 0.07 & 0.04 & 1.48 & 0.14 & -0.02 & 0.15 \\
\hline Family Transitions & -0.12 & 0.14 & -0.88 & 0.38 & -0.40 & 0.15 \\
\hline Knowledge & -0.16 & 0.04 & 4.45 & 0.00 & 0.09 & 0.22 \\
\hline Nonbiological Father & 0.06 & 0.50 & 0.11 & 0.91 & -.92 & 1.02 \\
\hline Co-parenting & 0.17 & 0.06 & 2.92 & 0.00 & 0.06 & 0.30 \\
\hline Var (Engagement) & 68.06 & 3.38 & & & 61.74 & 75.01 \\
\hline Var (Closeness) & 15.71 & 0.78 & & & 14.25 & 17.31 \\
\hline Cov (Engagement, Closeness) & -1.04 & 1.14 & -0.91 & 0.37 & & \\
\hline
\end{tabular}


$C I=(0.00,0.09), C F I=1.0, T L I=1.0, S R M R=0.002(\mathrm{Hu}$ $\&$ Bentler, 1999). In evaluating paths of paternal engagement, path analysis revealed that current factors of depression $(Z=3.68, p=0.001)$, parent knowledge $(Z=9.12$, $p=0.001)$, and warmth $(Z=2.68, p=0.007)$ along with historical factors of ACEs $(Z=3.42, p=0.001)$, family transitions $(Z=3.18, p=0.001)$, and own father relationship quality $(\mathrm{Z}=5.75, p=0.000)$, were associated with father engagement (Table 3 ).

Path analysis also evaluated the relationship between current and historical factors with father-adolescent relationship closeness. The path analysis indicates that current factors including co-parenting $(Z=2.92, p=0.004)$, parenting stress $(\mathrm{Z}=-3.99, p=0.008)$, parent depression $(\mathrm{Z}=-2.12, p=0.034)$, parent knowledge of adolescent $(\mathrm{Z}=4.45, p=0.000)$, and warmth $(\mathrm{Z}=14.77, p=0.000)$ were associated with parent-adolescent closeness. Historical factors including ACEs $(\mathrm{Z}=1.48, p=0.14)$, family transitions $(\mathrm{Z}=-0.88, p=0.379)$, biological fathering $(\mathrm{Z}=0.11$, $p=0.910)$, and own father relationship quality $(\mathrm{Z}=-0.52$, $p=0.600$ ), were not associated with parent adolescent closeness. Strangely, engagement and father-adolescent closeness were not correlated $(\mathrm{Z}=-0.91, p=0.37)$.

A follow up multi-group path analysis was conducted to compare the impact of the child's gender on predictors in the model designated in Fig. 1 while controlling for Race, Child Age, Father Residential Status, Employment, and Relationship with Child. The model was also found to be justly identified; $\chi 2=797.88, \mathrm{p}=0.000, R M S E A=0,90 \%$ $C I=(0.00,0.09), C F I=1, T L I=1.018, S R M R=0.002(\mathrm{Hu}$ $\&$ Bentler, 1999). For female children, path analysis for engagement with current factors indicated associations with parent knowledge $(\mathrm{Z}=4.94, p=0.000)$, depression $(\mathrm{Z}=3.36$, $p=0.001$, and warmth $(Z=3.19, p=0.001)$, while historical factor associations included ACEs $(\mathrm{Z}=3.18, p=0.000)$ and own father quality $(\mathrm{Z}=4.22, p=0.000)$. For male children, path analysis for engagement included current factors of parent knowledge $(\mathrm{Z}=7.42, p=0.000)$ and depression $(\mathrm{Z}=2.14, p=0.033)$. Historical factor associations included family transitions $(\mathrm{Z}=3.21, p=0.001)$ and own father relationship quality $(\mathrm{Z}=3.22, p=0.001)$.

A follow up multi group path analysis was also conducted to analyze associations of father-adolescent relationship closeness based on child gender. For female children, associations included current factors of parent knowledge $(Z=3.92, p=0.000)$, parenting stress $(Z=-2.04$, $p=0.041)$, and warmth $(\mathrm{Z}=8.10, p=0.000)$ with no associations to historical factors. For male children, current factor associations to relationship closeness included parent knowledge $(Z=2.60, p=0.009)$, coparenting $(Z=2.72$, $p=0.006)$, depression $(Z=-2.21, p=0.027)$, parenting stress $(Z=-3.45, p=0.001)$, and warmth $(Z=11.93$, $p=0.000)$ with no associations to historical factors.

\section{Discussion}

This study attempted to examine the factors that associate with both engagement and closeness between a father and an adolescent child. The main interest of this study was to identify both historical and current factors that could potentially contribute to future research of parent-adolescent relationship closeness. Additionally, the study sought to identify historical and current factors that contribute to engagement. The findings from this study indicate support for the hypothesis that both current and historical factors are highly influential for father engagement with an adolescent, while current factors may be a primary focus in producing close father-adolescent relationships.

Father-adolescent relationship quality is an underresearched area and needs further attention to identify ways to boost relationship quality during a time period that is often characterized by teenage separation from the family of origin (Meeus, 2019). Within this context, we attempted to separate both current and historical factors to provide some characterization of the types of factors that may influence the closeness of the father-adolescent relationship. While a father's relationship with his own father and his history of ACEs including family transitions were associated with his engagement, these factors were not associated with the quality of closeness of the relationship between fathers and adolescents. Furthermore, the history of having a nonbiological father was also not associated with father-adolescent relationship closeness. Thus, our hypothesis that these historical factors would be associated with father-adolescent closeness was not supported.

We also hypothesized that current factors including warmth, parent knowledge, stress, depression, and coparenting would associate with parent-adolescent relationship closeness. This hypothesis held with results indicating that greater warmth, parent knowledge, and co-parenting increased the closeness of the relationship, while stress and depression had a negative effect. These results are consistent with findings that warmth and knowledge of an adolescent are intimately tied; and with increased quality of the parent-child relationship, an adolescent is more willing to disclose (Dotterer \& Day, 2019). It also appears that co-parenting may have an effect on father-adolescent relationship closeness, consistent with previous findings of the indirect effect of co-parenting on the relationship between parent-child relationship quality and child externalizing behavior outcomes (Coates et al., 2019). Results here also indicate the negative effect that mood related problems (Shafer et al., 2019) and parenting stress (Knoester \& Petts, 2017) have on parent-child engagement; however, findings further support the role that these problems have on fatheradolescent closeness. 
Interestingly, when evaluating current factors on parent engagement, only parent knowledge, depression, and warmth were associated; thus, while co-parenting positively influenced parent-adolescent relationship closeness, it did not appear to associate with engagement. This finding was surprising, considering the multitude of studies that support associations between co-parenting and paternal engagement (Lee, Volling, Lee, \& Altschul, 2020; Fagan \& Palkovitz, 2019). However, studies of co-parenting influence on father engagement are often focused on the transition to parenthood and early childhood and have indicated a complicated triadic nature of co-parenting within the context of intimate partner interaction (Fagan \& Palkovitz, 2019). Unfortunately, while there has been some focus on coparenting during the adolescent years, relatively few studies have evaluated this factor on father-adolescent engagement or relationship quality. This finding potentially indicates the triadic influence of the parent's intimate partnership and co-parenting interaction on parenting outcomes, perhaps emphasizing how the evolving co-parenting quality could be leveraged to increase positive father-adolescent interaction. Further evaluation of this relationship could be explored using an actor partner interdependence model to understand the interactive nature of the co-parenting relationship and intimate partnership on father-adolescent relationship quality and/or a longitudinal evaluation of the changes in co-parenting and relationship closeness over time.

Surprisingly, in the path analysis, father-adolescent relationship closeness was not associated with engagement. We expect that this may be due to a mediator of this relationship that we have not yet analyzed. We expect that there may be personal characteristics that may mediate the relationship between engagement and father-adolescen closeness, serving as a moderator to this relationship. As parental warmth has been found to predict and moderate adolescent achievement outcomes (Chung, Phillips, Jensen, \& Lanier, 2019; Suizzo et al., 2017), adolescent prosocial behavior (Padilla-Walker et al., 2016), and adolescent externalizing behavior (Quach, Epstein, Riley, Falconier, \& Fang, 2015), we also suspect that warmth plays an important role in the interactions between fathers and adolescents. However, further analysis is necessary to evaluate the mediating relationship of this variable on engagement and father-adolescent relationship closeness.

As there was not a direct pathway between engagement and closeness, we propose that father-adolescent closeness is a separate dimension of the father-adolescent relationship experience and should be considered in evaluating outcomes and assessing interventions. Pleck's (2010) model of involvement does not explicitly state closeness as a dimension of engagement between a father and child, despite recent qualitative inquiry that bonding and closeness is an experience of some fathers (Trahan \& Cheung, 2018).
With evidence that the father-child relationship does have an important effect on adolescent outcomes and associates with engagement, these variables are interrelated. However, it appears that closeness remains a distinctly different dimension of father engagement, and as such may need inclusion as a component of its definition.

In the multi-group analysis, results indicated slight differences in associations based on gender. For father-adolescent closeness, both male and female adolescent positive associations included parent knowledge, stress, and warmth. However, male adolescent associations also included father depression and co-parenting. Thus, previous evidence that father-daughter adolescent closeness, as opposed to father-son adolescent closeness, is associated with paternal depression (Reeb \& Conger, 2009) was not supported. Multi-group analysis associations with father engagement indicate that warmth may be more important for the engagement of fathers with daughters than sons.

\section{Limitations and Future Directions}

These exploratory findings are limited in their generalizability. The data set is a quota sample, and not a nationally representative sample, which may not accurately produce generalizability to the larger population (Yang \& Banamah, 2014). Additionally, respondents were paid for their participation in the panel survey, which may influence their responses and increase self-selection bias (Bethlehem, 2010), and quota sampling may not provide for identity of the respondent (Im \& Chee, 2011). The survey is cross-sectional and does not make any inference of causation. The survey was also completed online, which may present bias of inclusion of respondents that do not represent socioeconomic variability, particularly lower-income fathers, and thus may be more of a function of social class. Access to a computer for families below the poverty line is $50 \%$ less likely than families with income exceeding $\$ 100,000$ per year (Dolan, 2016). The results of this study should thus be interpreted with caution and considered exploratory.

While these results may not be generalizable, they do point to a significant shift necessary in fatherhood related research. Recently, scholars have indicated that the quality of the father-child relationship is under-researched and requires more scientific inquiry (Fagan, 2020; Palkovitz, 2019). Within the context of scholars' suggestions to increase our understanding of the attachment of relationship within the family context (Bretherton, 2010; Palm, 2014), the interrelationship between paternal attachment and relationship closeness, the intimate interaction between the father and mother, and the attachment between a mother and a child may be interrelated; thus, we suggest that future inquiry focus on the triadic relationship of these attachment outcomes using an actor partner interdependence model (Wickham \& Knee, 
2012) to account for the potential influence of maternal-child closeness on paternal-child relationship quality.

\section{Implications}

This study adds to the knowledge base related to paternal-child relationship closeness, and provides a bridge between previously researched outcomes of co-parenting and father-adolescent engagement (Futris \& Schoppe-Sullivan, 2007). As a broader exploration of the variables included here, this research may assist future evaluation of focused attention on these factors to further clarify the effect of specific variables, with both direct and indirect effects, on father-adolescent relationship closeness. Within social work practice and fatherhood specific interventions, several findings point to important implications in working with fathers and adolescents. Father-adolescent closeness and father engagement are two distinctly different dimensions with a set of distinctive associated factors and may be influenced by distinctly different current and historical factors. Based on these findings, father-adolescent closeness may be most influenced through current factors such as parent depression, parenting stress, co-parenting, parent knowledge of the adolescent and warmth. There appears to be little evidence here that interventions focused on own father quality, history of ACEs or nonbiological fathering may boost father-adolescent relationship closeness. However, when focused on boosting active parent-adolescent engagement, practitioners may consider these historical influences in shaping their family interventions. Furthermore, we might note that there are slight differences in associations for father-daughter and father-son relationships. It may be noted that father-adolescent closeness and relationship quality is under-researched, and more study is needed to evaluate how father-adolescent closeness is experienced based on age of parent and child, cultural and ethnic background, and history of own father relationship quality.

Funding This research was funded by internal grants at Brigham Young University.

\section{Compliance with Ethical Standards}

Conflict of interest There are no conflicts of interest for the authors related to this paper.

\section{References}

Ainsworth, M. (1979). Infant-mother attachment. American Psychologist, 34(10), 932-937.
Ainsworth, M. (1989). Attachments beyond infancy. American Psychologist, 44(4), 709-716.

Amato, P. R., King, V., \& Thorsen, M. L. (2016). Parent-child relationships in stepfather families and adolescent adjustment: A latent class analysis. Journal of Marriage and Family, 78(2), 482-497. https://doi.org/10.1111/jomf.12267.

Anda, R. F., Butchart, A., Felitti, V. J., \& Brown, D. W. (2010). Building a framework for global surveillance of the public health implications of adverse childhood experiences. American Journal of Preventive Medicine, 39(2), 93-98.

Baker, R., Blumberg, S. J., Brick, J. M., Couper, M. P., Courtright, M., Dennis, J. M., ... Krosnick, J. (2010). Research synthesis: AAPOR report on online panels. Public Opinion Quarterly, 74(4), 711-781. https://doi.org/10.1093/poq/nfq048.

Banyard, V. L., Williams, L. M., \& Siegel, J. A. (2003). The impact of complex trauma and depression on parenting: An exploration of mediating risk and protective factors. Child Maltreatment, 4, 334 .

Beaton, J. M., \& Doherty, W. J. (2007). Fathers' family of origin relationships and attitudes about father involvement from pregnancy through first year postpartum. Fathering: A Journal of Theory, Research \& Practice about Men as Fathers, 5(3), 236-245. https ://doi.org/10.3149/fth.0503.236.

Bethell, C. D., Carle, A., Hudziak, J., Gombojav, N., Powers, K., Wade, R., \& Braveman, P. (2017). Methods to assess adverse childhood experiences of children and families: Toward approaches to promote child well-being in policy and practice. Academic Pediatrics, 17, S51-S69. https://doi.org/10.1016/j.acap.2017.04.161.

Bethlehem, J. (2010). Selection bias in web surveys. International Statistical Review, 78(2), 161-188. https://doi.org/10.111 1/j.1751-5823.2010.00112.x.

Bowlby, J. (1973). Attachment and loss: Vol. 2. Separation anxiety and anger. New York: Basic Books.

Bowlby, J. (1988). A secure base: Parent-child attachment and healthy human development. New York: Basic Books.

Bray, J. H., \& Easling, I. (2005). Remarriage and stepfamilies. In W. Pinsoff \& J. Lebow (Eds.), Family psychology: State of the art (pp. 267-294). New York: Oxford University Press.

Bretherton, I. (2010). Fathers in attachment theory and research: A review. Early Child Development and Care, 180(1-2), 9-23. https://doi.org/10.1080/03004430903414661.

Bronte-Tinkew, J., Moore, K. A., Matthews, G., \& Carrano, J. (2007). Symptoms of major depression in a sample of fathers of infants: Sociodemographic correlates and links to father involvement. Journal of Family Issues, 28(1), 61-99.

Brown, G. L., Mangelsdorf, S. C., \& Neff, C. (2012). Father involvement, paternal sensitivity, and father-child attachment security in the first 3 years. Journal of Family Psychology, 3, 421.

Browne, M. W., \& Cudeck, R. (1992). Alternative ways of assessing model fit. Sociological Methods \& Research, 21(2), 230-258. https://doi.org/10.1177/0049124192021002005.

Brown, S. L. (2006). Family structure transitions and adolescent wellbeing. Demography, 43(3), 447-461.

Busby, D. M., Holman, T. B., \& Taniguchi, N. (2001). RELATE: Relationship evaluation of the individual, family, cultural, and couple contexts. Family Relations, 50(4), 308-316. https://doi.org/10.1 111/j.1741-3729.2001.00308.x.

Cano, T., Perales, F., \& Baxter, J. (2019). A matter of time: Father involvement and child ognitive outcomes. Journal of Marriage and Family, 81(1), 164-184. https://doi.org/10.1111/jomf.12532.

Carlson, M. J. (2006). Family structure, father involvement, and adolescent behavioral outcomes. Journal of Marriage and Family, 68(1), 137.

Carlson, M. J., Pilkauskas, N. V., McLanahan, S. S., \& Brooks-Gunn, J. (2011). Couples as partners and parents over children's early years. Journal of Marriage and Family, 73, 317-334. 
Center for Disease Control. (2019a). Adverse childhood experiences (ACES). Retrieved at https://www.cdc.gov/violenceprevention/ childabuseandneglect/acestudy/index.html

Center for Disease Control. (2019b). National survey of family growth. Retrieved at https://www.cdc.gov/nchs/about/factsheets/facts heet_nsfg.htm.

Chung, G., Phillips, J., Jensen, T. M., \& Lanier, P. (2019). Parental involvement and adolescents' academic achievement: Latent profiles of mother and father warmth as a moderating influence. Family Process. https://doi.org/10.1111/famp.12450.

Coates, E. E., \& Phares, V. (2014). Predictors of paternal involvement among nonresidential, black fathers from low-income neighborhoods. Psychology of Men and Masculinity, 15(2), 138-151. https://doi.org/10.1037/a0032790.

Coates, E. E., Tran, Q., Le, Y., \& Phares, V. (2019). Parenting, coparenting, and adolescent adjustment in African American singlemother families: An actor-partner interdependence mediation model. Journal of Family Psychology, 33(6), 649-660. https:// doi.org/10.1037/fam0000552.

Coleman, A., Caldwell, C. H., O’Neil, J. M., \& Ferris, A. M. (2019). Black fathers matter: The role of paternal closeness on adolescent male obesity. Psychology of Men and Masculinity, 20(2), 174-181.

Coltrane, S. (1996). Family man: Fatherhood, housework, and gender equity. Oxford: Oxford Univ Press.

Comstock, G. W., \& Helsing, K. J. (1976). Symptoms of depression in two communities. Psychological Medicine, 6(4), 551-563. https ://doi.org/10.1017/S0033291700018171.

Cook, J. L., Jones, R. M., Dick, A. J., \& Singh, A. (2005). Revisiting men's role in father involvement: The importance of personal expectations. Fathering: A Journal of Theory, Research \& Practice about Men as Fathers, 3(2), 165-178. https://doi. org/10.3149/fth.0302.165.

Davison, K. K., Gicevic, S., Aftosmes-Tobio, A., Ganter, C., Simon, C. L., Newlan, S., \& Manganello, J. A. (2016). Fathers' representation in observational studies on parenting and childhood obesity: A systematic review and content analysis. American Journal of Public Health, 106(11), e14-e21. https://doi.org/10.2105/ AJPH.2016.303391.

Dick, G. (2011). The changing role of fatherhood: The father as a provider of self object functions. Psychoanalytic Social Work, 18(2), 107-125.

Diener, M. L., Isabella, R. A., Behunin, M. G., \& Wong, M. S. (2008). Attachment to mothers and fathers during middle childhood: Associations with child gender, grade, and competence. Social Development, 17(1), 84-101. https://doi.org/10.111 1/j.1467-9507.2007.00416.x.

DiLillo, D., Tremblay, G., \& Peterson, L. (2000). Linking childhood sexual abuse and abusive parenting: The mediating role of maternal anger. Child Abuse \& Neglect, 24(6), 767-779.

Dittus, P. J., Michael, S. L., Becasen, J. S., Gloppen, K. M., McCarthy, K., \& Gilamo-Ramos, V. (2015). Parental monitoring and its associations with adolescent sexual risk behavior: A metaanalysis. Pediatrics, 136(6), e1587-e1599.

Dolan, J. E. (2016). Splicing the divide: A review of research on the evolving digital divide among $\mathrm{K}-12$ students. Journal of Research on Technology in Education, 48(1), 16-37. https://doi. org/10.1080/15391523.2015.1103147.

Dotterer, A. M., \& Day, E. (2019). Parental knowledge discrepancies: Examining the roles of warmth and self-disclosure. Journal of Youth \& Adolescence, 48(3), 459-468. https://doi.org/10.1007/ s10964-018-0926-2.

Driscoll, K., \& Pianta, R. C. (2011). Mothers' and fathers' perceptions of conflict and closeness in parent-child relationships during early childhood. Journal of Early Childhood \& Infant Psychology, 7, 1-24.
Dyer, W. J., Kauffman, R., Fagan, J., Pearson, J., \& Cabrera, N. (2018). Measures of father engagement for nonresident fathers. Family Relations, 67(3), 381-398. https://doi.org/10.1111/fare.12317.

Epkins, C. C., \& Harper, S. L. (2016). Mothers' and fathers' parental warmth, hostility/rejection/neglect, and behavioral control: Specific and unique relations with parents' depression versus anxiety symptoms. Parenting Science and Practice, 16(2), 125-145. https://doi.org/10.1080/15295192.2016.1134991.

Fagan, J. (2020). Broadening the scope of father-child attachment research to include the family context. Attachment and Human Development, 22(1), 139-142. https://doi.org/10.1080/14616 734.2019.1589071.

Fagan, J., \& Palkovitz, R. (2007). Unmarried, nonresident fathers' involvement with their infants: A risk and resilience perspective. Journal of Family Psychology, 3, 479. https://doi. org/10.1037/0893-3200.21.3.479.

Fagan, J., \& Palkovitz, R. (2019). Coparenting and father engagement among low-income parents: Actor-partner interdependence model. Journal of Family Psychology. https://doi. org/10.1037/fam0000563.

Fanti, K., Henrich, C., Brookmeyer, K., \& Kuperminc, G. (2008). Toward a transactional model of parent-adolescent relationship quality and adolescent psychological adjustment. Journal of Early Adolescence, 28(2), 252-276.

Fishbein, M., \& Ajzen, I. (1975). Belief, attitude, intention and behavior: An introduction to theory and research. Reading, MA: Addison-Wesley.

Folger, A. T., Eismann, E. A., Stephenson, N. B., Shapiro, R. A., Macaluso, M., Brownrigg, M. E., \& Gillespie, R. (2018). Parental adverse childhood experiences and offspring development at 2 years of age. Pediatrics, 141(4), e20172826.

Futris, T. G., \& Schoppe-Sullivan, S. J. (2007). Mothers' perceptions of barriers, parenting alliance, and adolescent fathers' engagement with their children. Family Relations, 56(3), 258-269. https://doi.org/10.1111/j.1741-3729.2007.00457.x.

Garfield, C. F., Fisher, S. D., Barretto, D., Rutsohn, J., \& Isacco, A. (2019). Development and validation of a father involvement in health measure. Psychology of Men \& Masculinities, 20(1), 148-160. https://doi.org/10.1037/men0000144.

Gaunt, R., \& Bassi, L. (2012). Modeling and compensatory processes underlying involvement in childcare among kibbutzreared fathers. Journal of Family Issues, 33(6), 823-848. https ://doi.org/10.1177/0192513X11428440.

Goncy, E. A., \& van Dulmen, M. H. M. (2010). Fathers do make a difference: Parental involvement and adolescent alcohol use. Fathering: A Journal of Theory, Research \& Practice about Men as Fathers, 8(1), 93-108. https://doi.org/10.3149/ fth.0801.93.

Goodsell, T. L., \& Meldrum, J. T. (2010). Nurturing fathers: A qualitative examination of child-father attachment. Early Child Development and Care, 180(1-2), 249-262.

Gordon, M. S. (2016). Community disadvantage and adolescent's academic achievement: The mediating role of father influence. Journal of Child and Family Studies, 25(7), 2069-2078. https:// doi.org/10.1007/s10826-016-0380-2.

Grossman, K., Grossman, K. E., Fremmer-Bombik, E., ScheuererEnglisch, H., \& Zimmerman, P. (2002). The uniqueness of the child-father attachment relationship: Fathers' sensitivity and challenging play as a pivotal variable in a 16-year longitudinal study. Social Development, 11(3), 307-331.

Grossman, K., Grossman, K. E., \& Kindler, H. (2005). Early care and the roots of attachment and partnership representations: The Bielefeld and Regensburg longitudinal studies. In K. E. Grossman, K. Grossman, \& E. Waters (Eds.), Attachment from infancy to adulthood: The major longitudinal studies (pp. 98-136). New York: Guilford Press. 
Guilamo-Ramos, V., Jaccard, J., \& Dittus, P. (Eds.). (2010). Parental monitoring of adolescents: Current perspectives of researchers and practitioners. Columbia University Press.

Habib, C., Santoro, J., Kremer, P., Toumborou, J., Leslie, E., \& Williams, J. (2010). The importance of family management closeness with father, and family structure in early adolescent alcohol use. Addiction, 105, 1750-1758.

Hair, E. C., Moore, K. A., Garrett, S. B., Kinukawa, A., Lippman, L., \& Michelson, E. (2006). The parent-adolescent relationship scale. Adolescent \& Family Health, 4(1), 12-25.

Harewood, T., Volloton, C. D., \& Brophy-Herb, H. (2017). More than just the breadwinner: The effects of fathers' parenting stress on children's language and cognitive development. Infant and Child Development, 26(2), 1-19.

Hesse, E., \& Main, M. (2006). Frightened, threatening, and dissociative parental behavior in low-risk samples: Description, discussion, and interpretations. Development and Psychopathology, 18(2), 309-343.

Hoeve, M., Dubas, J. S., Eichelsheim, V. I., van der Laan, P. H., Smeenk, W., \& Gerris, J. R. M. (2009). The relationship between parenting and delinquency: A meta-analysis. Journal of Abnormal Child Psychology, 37, 749-775.

Hofferth, S. L., \& Anderson, K. G. (2003). Are all dads equal? Biology versus marriage as a basis for paternal investment. Journal of Marriage and Family, 65(1), 213-232.

Hosley, R., Canfield, K., O'Donnell, S., \& Roid, G. (2008). Father closeness: Its effect on married men's sexual behaviors, marital, and family satisfaction. Sexual Addiction \& Compulsivity, 15(1), 59-76. https://doi.org/10.1080/10720160701878761.

Hosmer, D. W., Lemeshow, S., \& Sturdivant, R. X. (2013). Model building strategies and methods for logistic regression. Applied Logistic Regression, Third Edition, 89.

Hu, L., \& Bentler, P. M. (1999). Cutoff criteria for fit indexes in covariance structure analysis: Conventional criteria versus new alternatives. Structural Equation Modeling, 6(1), 1-55. https://doi. org/10.1080/10705519909540118.

Hughes, M., \& Cossar, J. (2016). The relationship between maternal childhood emotional abuse/neglect and parenting outcomes: A systematic review. Child Abuse Review, 25(1), 31-45. https://doi. org/10.1002/car.2393.

Im, E.-O., \& Chee, F. W. (2011). Quota sampling in internet research practical issues. CIN-Computers Informatics Nursing, 29(7), 381-385. https://doi.org/10.1097/NCN.0b013e3181f9dc45.

Jensen, T., Shafer, K., \& Holmes, E. K. (2017). Transitioning to stepfamily life: The influence of closeness with biological parents and stepparents on children's stress. Child and Family Social Work, 22(1), 275-286.

Jessee, V., \& Adamsons, K. (2018). Father involvement and fatherchild relationship quality: An intergenerational perspective. Parenting: Science \& Practice, 18(1), 28-44. https://doi. org/10.1080/15295192.2018.1405700

Jones, K. (2004). Assessing psychological separation and academic performance in non-residential father and resident father adolescent boys. Clinical Social Work Journal, 21(4), 333-354.

Keijsers, L. (2016). Parenting monitoring and adolescent problem behaviors. International Journal of Behavioral Development, 40(3), 271-281.

Keizer, R., Helmerhorst, K. O. W., \& van Rijn-van Gelderen, L. (2019). Perceived quality of the mother-adolescent and father-adolescent attachment relationship and adolescents' self-esteem. Journal of Youth and Adolescence: A Multidisciplinary Research Publication, 48(6), 1203-1217.

Knoester, C., \& Petts, R. J. (2017). Fathers' parenting stress after the arrival of a new child. Family Relations, 66(3), 367-382. https ://doi.org/10.1111/fare.12263.
Lamb, M. (1975). Infant attachment to mothers and fathers. Paper presented at the Biennial Meeting of the Society for Research in Child Development (Denver, Colorado, April 10-13, 1975). $1-11$.

Lance, C. E., Beck, S. S., Fan, Y., \& Carter, N. T. (2016). A taxonomy of path-related goodness-of-fit indices and recommended criterion values. Psychological Methods, 21(3), 388-404. https://doi. org/10.1037/met0000068.

Leon, S. C., Jhe Bai, G., \& Fuller, A. K. (2016). Father involvement in child welfare: Associations with changes in externalizing behavior. Child Abuse \& Neglect, 55, 73-80. https://doi.org/10.1016/j. chiabu.2016.04.003.

Lee, D., \& McLanahan, S. (2015). Family structure transitions and child development: Instability, selection and population heterogeneity. American Sociological Review, 80(4), 738.

Lee, J. Y., Volling, B. L., Lee, S. J., \& Altschul, I. (2020). Longitudinal relations between coparenting and father engagement in lowincome residential and nonresidential father families. Journal of Family Psychology, 34(2), 226-236. https://doi.org/10.1037/ t02441-000.

Leung, D. W., \& Smith Slep, A. M. (2006). Predicting inept discipline: The role of parental depressive symptoms, anger, and attributions: Children and adolescents. Journal of Consulting and Clinical Psychology, 3, 524.

Lionetti, F., Palladino, B. E., Passini, C. M., Casonato, M., Hamzallari, O., Ranta, M., ... Keijsers, L. (2019). The development of parental monitoring during adolescence: A meta-analysis. European Journal of Developmental Psychology, 16(5), 552-580. https:// doi.org/10.1080/17405629.2018.1476233.

Little, R. J. A. (1988). A test of missing completely at random for multivariate data with missing values. Journal of the American Statistical Association, 83(404), 1198. https://doi.org/10.2307/22901 57.

Lucassen, N., Verhulst, F. C., Lambregtse-Van den Berg, M. P., Tiemeier, H, Tharner, A., Van IJzendoorn, M. H., ... Volling, B. L. (2011). The association between paternal sensitivity and infantfather attachment security: A meta-analysis of three decades of research. Journal of Family Psychology, 25(6), 986-992.

Madigan, S., Atkinson, L., Laurin, K., \& Benoit, D. (2013). Attachment and internalizing behavior in early childhood: A meta-analysis. Developmental Psychology, 49(4), 672-689.

Madigan, S., Benoit, D., \& Boucher, C. (2011). Exploration of the links among fathers' unresolved states of mind with respect to attachment, atypical paternal behavior, and disorganized infant-father attachment. Infant Mental Health Journal, 32(3), 286-304. https ://doi.org/10.1002/imhj.20297.

McElwain, A., \& Bub, K. (2018). Changes in parent-child relationship quality across early adolescence: Implications for engagement in sexual behavior. Youth and Society, 50(2), 204-228. https://doi. org/10.1177/0044118X15626843.

McHale, J. P., \& Lindahl, K. M. (2011). Coparenting: A conceptual and clinical examination of family systems. Washington, D.C.: American Psychological Association.

Meeus, W. (2019). Adolescent development: Longitudinal research into the self, personal relationships, and psychopathology. New York: Routledge.

Moreno, O., Janssen, T., Cox, M. J., Colby, S., \& Jackson, K. M. (2017). Parent-adolescent relationships in Hispanic versus Caucasian families: Associations with alcohol and marijuana use onset. Addictive Behaviors, 74, 74-81. https://doi.org/10.1016/j. addbeh.2017.05.029.

Murphy, A., Steele, M., Dube, S. R., Bate, J., Bonuck, K., Meissner, P., ... Steele, H. (2014). Adverse childhood experiences (ACEs) questionnaire and adult attachment interview (AAI): Implications for parent child relationships. Child Abuse \& Neglect, 2, 224. 
Nath, S., Russell, G., Ford, T., Kuyken, W., \& Psychogiou, L. (2015). Postnatal paternal depressive symptoms associated with fathers' subsequent parenting: Findings from the millennium cohort study. British Journal of Psychiatry, 207(6), 558-559. https:// doi.org/10.1192/bjp.bp.114.148379.

Nygren, M., Carstensen, J., Ludvigsson, J., \& Sepa Frostell, A. (2012). Adult attachment and parenting stress among parents of toddlers. Journal of Reproductive and Infant Psychology, 30(3), 289-302.

O'Gara, J. L., Zhang, A., Padilla, Y., Liu, C., \& Wang, K. (2019). Father-youth closeness and adolescent self-rated health: The mediating role of mental health. Children and Youth Services Review, https://doi.org/10.1016/j.childyouth.2019.104386.

Osborne, C., \& Mclanahan, S. (2007). Partnership instability and child well-being. Journal of Marriage and Family, 69(4), 1065-1083.

Padilla-Walker, L. M., Nielson, M. G., \& Day, R. D. (2016). The role of parental warmth and hostility on adolescents' prosocial behavior toward multiple targets. Journal of Family Psychology, 30(3), 331-340. https://doi.org/10.1037/fam0000157.

Palkovitz, R. (2019). Expanding our focus from father involvement to father-child relationship quality. Journal of Family Theory and Review, 11(4), 576-591. https://doi.org/10.1111/jftr.12352.

Palm, G. (2014). Attachment theory and fathers: Moving from "being there" to "being with". Journal of Family Theory \& Review, 6(4), 282-297. https://doi.org/10.1111/jftr.12045.

Pazdera, A. L., McWey, L. M., Mullis, A., \& Carbonell, J. (2013). Child sexual abuse and the superfluous association with negative parenting outcomes: The role of symptoms as predictors. Journal of Marital \& Family Therapy, 39(1), 98-111. https://doi.org/10. 1111/j.1752-0606.2011.00272.x.

Pleck, J. H. (2007). Why could father involvement benefit children? Theoretical perspectives. Applied Developmental Science, 11(4), 196-202. https://doi.org/10.1080/10888690701762068.

Pleck, J. H. (2010). Paternal involvement: Revised conceptualization and theoretical linkages with child outcomes. In M. E. Lamb (Ed.), The role of the father in child development., 5th ed. (201004805-003; pp. 58-93). John Wiley \& Sons Inc.

Phares, V., Renk, K., Duhig, A. M., Fields, S., \& Sly, J. (2008). Gender differences in positive and negative feeligns between adolescents and their fathers and mothers. Journal of Child and Family Studies, 18, 213-218. https://doi.org/10.1007/s10826-008-9221-2.

Pinquart, M. (2015). Associations of parenting styles and dimensions with academic achievement with children and adolescents: A meta-analysis. Educational Psychology Review, 28, 475-493.

Pinquart, M. (2017). Associations of parenting dimensions and styles with externalizing problems of children and adolescents: An updated meta-analysis. Developmental Psychology, 53(5), 873932. https://doi.org/10.1037/t01309-000.

Quach, A., Epstein, N., Riley, P., Falconier, M., \& Fang, X. (2015). Effects of parental warmth and academic pressure on anxiety and depression symptoms in Chinese adolescents. Journal of Child \& Family Studies, 24(1), 106-116. https://doi.org/10.1007/ s10826-013-9818-y.

Reeb, B. T., \& Conger, K. J. (2009). The unique effect of paternal depressive symptoms on adolescent functioning: Associations with gender and father-adolescent relationship closeness. Journal of Family Psychology, 23(5), 758-761. https://doi.org/10.1037/ a0016354.

Rosen, J. E. (2004). Adolescent health and development (AHD): A resource guide for World Bank operations staff and government counterparts / Dominican Republic - poverty assessment : Achieving more pro-poor growth. Retrieved from https://docum ents.worldbank.org/curated/en/275631468762356035/pdf/30254 0HNP0Adolescent0health.pdf

Rostad, W. L., Silverman, P., \& McDonald, M. K. (2014). Daddy's little girl goes to college: An investigation of females' perceived closeness with fathers and later risky behaviors. Journal of American College Health, 62(4), 213-220. https://doi. org/10.1080/07448481.2014.887570.

Ruiz, N., Piskernik, B., Witting, A., Fulko, R., \& Ahnert, L. (2018). Parent-child attachment in children borth preterm and at term. A multigroup analysis. PLoS ONE, 13(8), e202972. https://doi. org/10.1371/journal.pone.0202972.

Sarkadi, A., Kristiansson, R., Oberklaid, F., \& Bremberg, S. (2008). Fathers' involvement and children's developmental outcomes: A systematic review of longitudinal studies. Acta Paediatrica, 97(2), 153-158. https://doi.org/10.1111/j.1651-2227.2007.00572 .x.

Schuetze, P., \& Eiden, R. D. (2005). The relationship between sexual abuse during childhood and parenting outcomes: Modeling direct and indirect pathways. Child Abuse and Neglect, 29(6), 645-659. https://doi.org/10.1016/j.chiabu.2004.11.004.

Shafer, K., Fielding, B., \& Holmes, E. K. (2019). Depression, masculine norm adherence, and fathering behavior. Journal of Family Issues, 40(1), 48-84. https://doi.org/10.1177/0192513X1880078 2.

Shafer, K., Fielding, B., \& Wendt, D. (2017). Similarities and differences in the influence of paternal and maternal depression onadolescent well-being. Social Work Research, 41(2), 85-96. https:// doi.org/10.1037/t52485-000.

Singley, D. B., Cole, B. P., Hammer, J. H., Molloy, S., Rowell, A., \& Isacco, A. (2018). Development and psychometric evaluation of the paternal involvement with infants scale. Psychology of Men and Masculinity, 19(2), 167-183. https://doi.org/10.1037/ men0000094.

StataCorp., (2017). Stata Statistical Software: Release 15. College Station, TX: StataCorp LLC.

Stattin, K., Kerr, M., \& Tilton-Weaver, L. (2010). Parental monitoring: A critical examination of research. In V. Guilamo-Ramos, J. Jaccard, \& P. Dittus (Eds.), Parental monitoring of adolescents: Current perspectives for researchers and practitioners (pp. 1-38). New York: Columbia University Press.

Steele, E. H., \& McKinney, C. (2019). Emerging adult psychological problems and parenting style: Moderation by parent-child relationship quality. Personality and Individual Differences, 146, 201-208.

Suizzo, M., Rackley, K. R., Robbins, P. A., Jackson, K. M., Rarick, J. R. D., \& McClain, S. (2017). The unique effects of fathers' warmth on adolescents' positive beliefs and behaviors: Pathways to resilience in low-income families. Sex Roles, 77(1-2), 46-58. https://doi.org/10.1007/s11199-016-0696-9.

Thomson, P., \& Jaque, S. V. (2017). Adverse childhood experience (ACE) and adult attachment interview (AAI) in a non-clinical population. Child Abuse and Neglect, 70, 255-263.

Thornberry, T. P., Knight, K. E., \& Lovegrove, P. J. (2012). Does maltreatment beget maltreatment? A systematic review of the intergenerational literature. Trauma, Violence \& Abuse, 13(3), 135-152. https://doi.org/10.1177/1524838012447697.

Tornello, S. L., \& Patterson, C. J. (2018). Adult children of gay fathers: Parent-child relationship quality and mental health. Journal of Homosexuality, 65(9), 1152-1166. https://doi.org/10.1080/00918 369.2017.1406218.

Tourangeau, R., Conrad, F. G., \& Couper, M. P. (2013). The science of web surveys. Oxford: Oxford University Press.

Trahan, M. H., \& Cheung, M. (2018). Fathering involvement to engagement: A phenomenological qualitative roadmap. Child and Adolescent Social Work Journal, 35(4), 367. https://doi.org/10.1007/ s10560-018-0529-5.

U.S. Census Bureau. (2016). American community survey. Retrieved at https://www.census.gov/programs-surveys/acs. 
U.S. Department of Health and Human Services. (2019). NICHD study of early child care and youth development (SECCYD). Retrieved at https://www.nichd.nih.gov/research/supported/seccyd.

Van Eijck, F. E. A. M., Branje, S. J. T., Hale, W. W., \& Meeus, W. H. J. (2012). Longitudinal associations between perceived parent-adolescent attachment relationship quality and generalized anxiety disorder symptoms in adolescence. Journal of Abnormal Child Psychology, 6, 871

Webster, L., Low, J., Siller, C., \& Hackett, R. K. (2013). Understanding the contribution of a father's warmth on his child's social skills. Fathering, 11(1), 90-113.

Weinberg, J. D., Freese, J., \& McElhattan, D. (2014). Comparing data characteristics and results of an online factorial survey between a population-based and a crowdsource-recruited sample. Sociological Science, 19, 292.

West, S. G., Taylor, A. B., \& Wu, W. (2012). Model fit and model selection in structural equation modeling. In R. H. Hoyle (Ed.), Handbook of structural equation modeling. (2012-16551-013; pp. 209-231). The Guilford Press.

Wickham, R. E., \& Knee, C. R. (2012). Interdependence theory and the actor-partner interdependence model: Where theory and method converge. Personality and Social Psychology Review (Print), 4, 375-393.

Wynter, K., Rowe, H., Tran, T., \& Fisher, J. (2016). Factors associated with father-to-infant attachment at 6 months postpartum: A community based study in Victoria, Australia. Journal of Reproductive and Infant Psychology, 34(2), 185-195.

Yang, K., \& Banamah, A. (2014). Quota sampling as an alternative to probability sampling? An experimental study. SociologicalResearch Online, 19(1), 56-66. https://doi.org/10.5153/sro.3199.

Yap, M. H. H., Cheong, T. W. K., Zaravinos-Tsakos, F., Lubman, D. I., \& Jorm, A. F. (2017). Modifiable parenting factors associated with adolescent alcohol misuse: A systematic review and metaanalysis of longitudinal studies. Addiction, 112(7), 1142-1162. https://doi.org/10.1111/add.13785.

Yap, M. B. H., Pilkington, P. D., Ryan, S. B., \& Jorm, A. F. (2014). Parental factors associated with depression and anxiety in young people: A systematic review and meta-analysis. Journal of Affective Disorders, 156, 8-23.

Yoon, S., Tebben, E., Bellamy, J., Lee, J., Yoon, D., \& Kim, W. (2020). Predictors of father-child relationship quality among adolescents at risk of maltreatment. Journal of Society for Social Work and Research, 11(1), 39-59.

Publisher's Note Springer Nature remains neutral with regard to jurisdictional claims in published maps and institutional affiliations. 